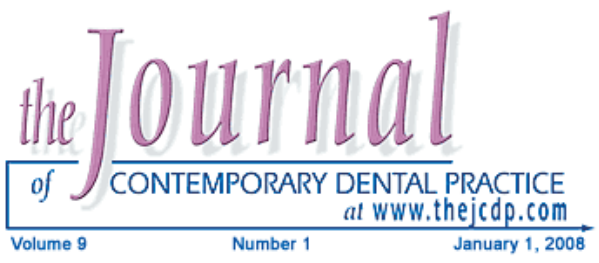

\title{
Oral Adverse Effects Due to the Use of Nevirapine
}

\author{
Mariela Dutra Gontijo Moura, DDS, MS; \\ Maria Inês Barreiros Senna, DDS, MS; \\ Davidson Fróis Madureira, DDS; \\ Linaena Méricy Silva Fonseca, DDS, PhD; \\ Ricardo Alves Mesquita, DDS, PhD
}

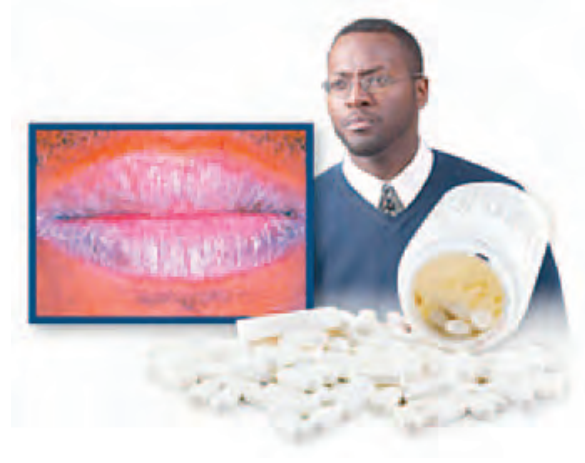

Abstract

Aim: The aim of this article is to present the clinical characteristics and management of an oral adverse effect stemming from the use of the antiretroviral medication Nevirapine (NVP).

Background: NVP is a non-nucleoside reverse transcriptase inhibitor used in the treatment of Human Immunodeficiency Virus (HIV) infection.

Case Report: A 29-year-old black man, HIV-infected since 1996, began highly active antiretroviral therapy (HAART) with zidovudine, lamivudine, and indinavir. From 1996 to 2002 several medications were changed due to their adverse effects: indinavir (renal colic and fever), nelfinavir (cutaneous rash), and efavirenz (nausea and temporary memory loss). When the patient presented to our service he was taking NVP, zidovudine, and lamivudine. A whitish plaque in the lips and bilateral buccal mucosa, burning, taste disturbance, and xerostomia were observed. The discontinuation of HAART led to the complete resolution of signs and symptoms. The patient has received follow-up treatment for three years and five months without local or systemic effects observed.

Summary: Unfortunately, the clinical features of the oral adverse effect from NVP are not well known. This paper contributed to the identification of possible reactions in the oral cavity due to antiretroviral medication.

Although HAART is very important in the treatment of HIV, its side effects are responsible for patients' nonadherence to medications. While more studies are needed to better understand the mechanism of action after suspending HAART, the complete resolution of the signs and symptoms was observed. Therefore, physicians

(c) Seer Publishing 
and dentists alike must understand how to identify and prevent these adverse effects in order to further improve HIV patient treatments.

Keywords: Adverse effects, antiretroviral, HIV infection, HAART, NNRTI, nevirapine.

Citation: Moura MGD, Senna MIB, Madureira DF, Fonseca LMS, Mesquita RA. Oral Adverse Effects Due to the Use of Nevirapine. J Contemp Dent Pract 2008 January; (9)1:084-090.

\section{Introduction}

Recent progress has been observed in developing therapies to treat HIV infection, particularly the highly active antiretroviral therapy (HAART). HAART represents a combination of antiretroviral agents, reverse transcriptase inhibitors, and protease. ${ }^{1-8}$ This therapeutic strategy results in a significant reduction of morbidity, prevalence of some oral lesions, and mortality associated with HIV infection. HAART, therefore, can substantially extend an HIV patient's life. ${ }^{4-10}$ However, one of the major problems with HAART are its adverse systemic and orofacial effects (Table 1).

Nevirapine (NVP) is a non-nucleoside reverse transcriptase inhibitor (NNRTI) which has occasionally been associated with systemic and orofacial adverse effects. ${ }^{1,3,7,12-15}$ The aim of this article is to present the clinical characteristics and management of an oral adverse effect stemming from the use of NVP in a 29-year-old HIV-infected black man.

\section{Case Report}

In July 2002 a 29-year-old black man was referred to the Dental Service of the Orestes Diniz's Treatment Center for Parasitic and Infectious Diseases in Belo Horizonte, MG, Brazil. The patient presented with whitish plaque on his oral mucosa, which had evolved over one month. His medical history revealed an HIV infection since 1996, the presence of gonorrhea, hepatitis $\mathrm{B}$, bronchitis, and bilateral maxillary sinusitis. In March 1998 his physician chose to begin antiretroviral therapy using zidovudine as the patient presented with a T CD4 lymphocyte count of $158 \mathrm{cells} / \mathrm{mm}^{3}$. In March 1999 the patient was taking zidovudine, lamivudine, and indinavi when he presented with renal colic and fever. In July 1999 the indinavir was replaced with nelfinavir but the patient developed a cutaneous rash. Subsequently, the nelfinavir was replaced with efavirenz but the patient presented with nausea and temporary memory loss. A month before the patient presented at the Dental Service clinic in

Table 1. The possible systemic and orofacial effects of HAART., H, $^{4,10,11}$

\begin{tabular}{|l|l|}
\hline \multicolumn{1}{|c|}{ Systemic Effects } & \multicolumn{1}{|c|}{ Orofacial Effects } \\
\hline - Lactic acidosis & - Erythema multiforme \\
- Hepatic steatosis & - Ulcers \\
- Hyperlactatemia & - Xerostomia \\
- Hepatotoxicity & - Cheilitis \\
- Hyperglycemia & - Parotid lipomatosis \\
- Fat maldistribution & - Taste disturbance \\
- Dyslipidemia & - Perioral paraesthesia \\
- Increased bleeding episodes among & - Facial edema \\
- patients with hemophilia & \\
- Osteonecrosis & \\
- Osteopenia & \\
- Skin rashes & \\
\hline
\end{tabular}


June of 2002 when the efavirenz was exchanged for NVP so his medication included NVP, zidovudine, and lamivudine at that time.

The patient's CD4 lymphocyte count was 532 cells $/ \mathrm{mm}^{3}$; the CD8 lymphocyte count was 582 cells $/ \mathrm{mm}^{3}$; the CD4/CD8 lymphocyte count was 0.91 ; and viral load was 255 copies $/ \mathrm{mL}$. The oral examination revealed a non-removable whitish plaque on the lips and bilateral buccal mucosa (Figures $1 \mathrm{~A}$ and $1 \mathrm{~B}$ ) and the dorsum of the tongue without papillae.

The patient complained of a taste disturbance, xerostomia, and a burning sensation in the mucosa. He reported no use of secondary medication, mouthwashes, or a change of toothpastes. The medical history suggested a provisory clinical diagnosis of an adverse oral effect due to the use of NVP. Consequently, antiretroviral therapy was suspended by his physician.

The physician chose to prescribe no antiretrovirals or secondary medication because of the patient's history of several adverse effects to different HAART medications; the patient was well without any opportunistic infection and his CD4 lymphocyte count was above 200 cells $/ \mathrm{mm}^{3}$. After one week, the patient returned with a significant improvement in the symptoms of burning, taste, xerostomia, and a partial disappearance of the whitish plaques on buccal mucosa and lips. Seven months later a total remission of the oral effect of the NVP was achieved (Figure 1C and 1D).

Without antiretroviral therapy during three years and five months of follow-up treatment the patient showed no negative oral effects. He also presented with no opportunistic infection or any other complaints. The patient's CD4 lymphocyte count was 343 cells $/ \mathrm{mm}^{3}$, the CD8 was 607 cells/ $\mathrm{mm}^{3}$, the CD4/CD8 was 0.57 , and the viral load was 2.489 copies $/ \mathrm{mL}$. As a result, the clinical diagnosis was finalized as an oral adverse effect due to the use of NVP. The patient has been receiving follow-up treatment by dentists and physicians since that time.

\section{Discussion}

This article supports a case report of an adverse oral effect due to the use of NVP. The oral whitish
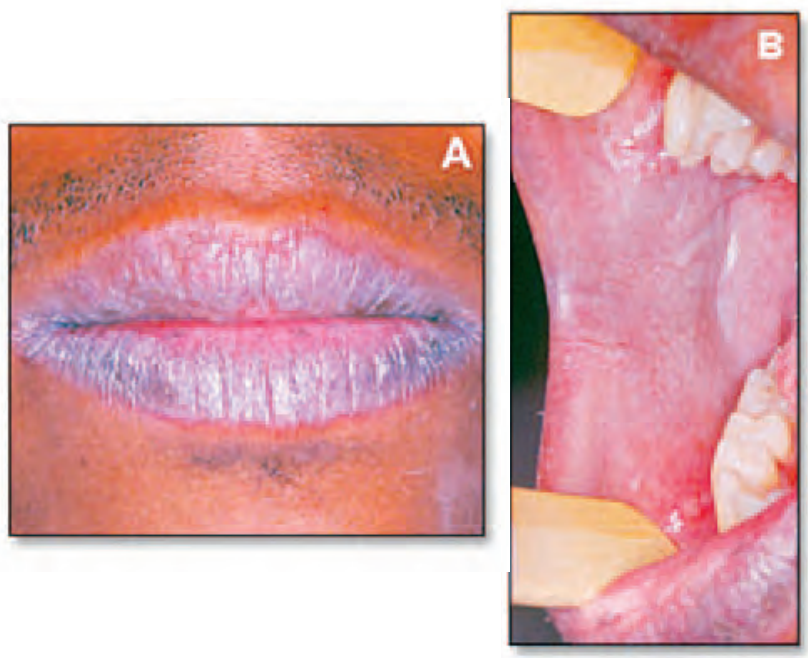

Figure 1. A and B. Clinical aspect of the oral adverse effect due to the use of nevirapine, showing whitish plaque on the lips and right buccal mucosa.

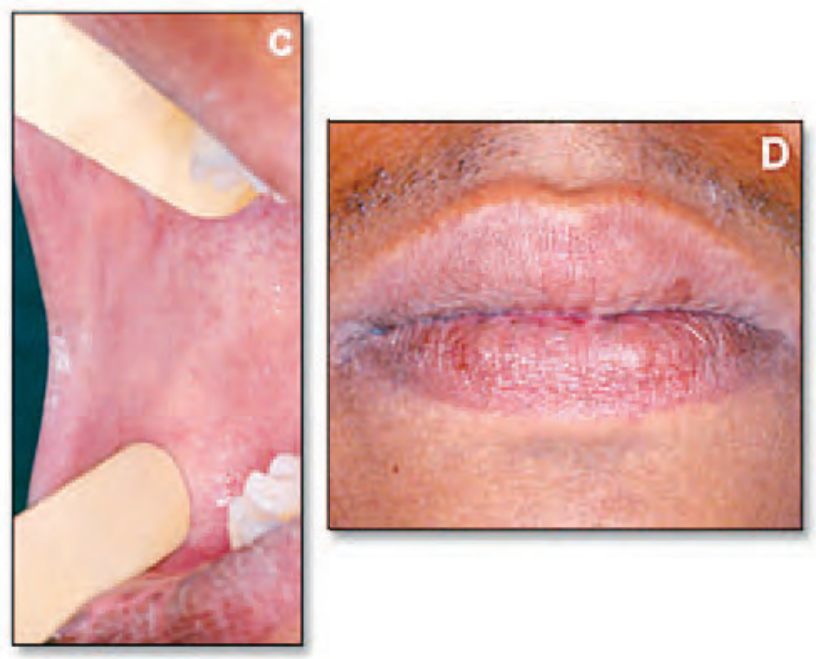

Figure 1. C and D. Right buccal mucosa and lips with normal aspect after seven mouths without antiretroviral therapy.

plaque began to appear when the patient began treatment with NVP. To our knowledge, this is the first case in the literature reporting on this type of oral effect stemming from NVP usage. Other orofacial adverse effects of HAART- related medications are displayed in Table 2. A biopsy was not performed as the patient's medical history was highly suggestive of an adverse effect caused by NVP. In addition, the discontinuation of his medication led to the complete clinical resolution of signs and symptoms. The taste disturbance and oral burning sensation may have also been caused by NVP as the patient's other antiretroviral medications (zidovudine and lamivudine), taken by the patient at the moment of 
Table 2. Orofacial adverse effects of specific antiretroviral therapies.*

\begin{tabular}{|l|l|}
\hline Possible Oral adverse Effects & \multicolumn{1}{|c|}{ Proper Name of Drugs } \\
\hline Cheilitis & Indinavir \\
\hline Erytema multiforme & $\begin{array}{l}\text { Abacavir, Delavidine, Didanosine, } \\
\text { Efavirenz, Nevirapine, Saquinavir, } \\
\text { Zalcitabin, and Zidovudine }\end{array}$ \\
\hline Facial edema & Ritonavir \\
\hline Hyperpigmentation & Zidovudine \\
\hline Parotid lipomatosis & $\begin{array}{l}\text { Amprenavir, Indinavir, Nelfinavir, } \\
\text { Ritonavir, and Saquinavir }\end{array}$ \\
\hline Perioral paraesthesia & Amprenavir and Ritonavir \\
\hline Taste diturbance & Indinavir and Ritonavir \\
\hline Ulcers & Nevirapine, Saquinavir, and Zalcitabine \\
\hline Xerostomia & Nelfinavir, Ritonavir, and Saquinavir \\
\hline
\end{tabular}

* In accordance to the Scully and Dios. ${ }^{7}$

evaluation, were not related to these symptoms. The xerostomia may be related to lamivudine as reported by Scully and Dios. ${ }^{7}$

Overall, NVP has a favorable safety profile suggesting it is safe and well-tolerated in both adult and pediatric patients. ${ }^{1,3,7,14-16}$ According to Pollard et al., ${ }^{16}$ adverse event data from long-term clinical trials demonstrated a lower incidence of NVP-related adverse events than in short-term trials of NVP therapy. With data from long-term studies supporting continuous treatment being one of the tenets of antiretroviral therapy, NVP would appear to present good tolerability when compared with the safety profiles of other HIV therapies. Orofacial adverse side effects of NVP include erythema multiforme and ulcers. Systemically, NVP has produced elevated liver enzymes, fever, nausea, vomiting, diarrhea, headache, abdominal pain, mialgia, rhinitis, influenza-like symptoms, and erythema multiforme ${ }^{1,3,7,14-16}$ Recent studies have shown NVP may also lead to an increase in both highdensity lipoprotein and low-density lipoprotein cholesterol levels. ${ }^{1,16-18}$ However, the most common adverse effect from the NNRTI group is a skin rash. ${ }^{1,3,5}$ Approximately $16 \%$ of the patients who had taken NVP presented with a mild to moderate maculopapular rash (with or without purities) on the trunk, face, and extremities. These alterations most commonly begin after two weeks of therapy. ${ }^{5,19}$ In the present case the patient did not present with skin or systemic alteration related to NVP.

HAART was suspended indefinitely, and the patient is currently under medical control showing no opportunistic infection or any other complaints. The suspension of the antiretroviral therapy is a form of medical management in cases of adverse effects. In addition, the patient presented a stable immunological profile with a high CD4 cell count (532 cells $/ \mathrm{mm}^{3}$ ) and a decrease in viral load (255 copies $/ \mathrm{mL})$.

HAART has significantly improved the prognosis of HIV patients and has proven to control viral replication. ${ }^{4,6,8,9}$ Three years and five months after 
having suspended treatment the patient's CD4 lymphocyte count was never lower than the limit of 200 cells $/ \mathrm{mm}^{3}$ but it was reduced to 343 cells/ $\mathrm{mm}^{3}$. In contrast, the patient's viral load increased by approximately ten fold, reaching 2.489 copies/ $\mathrm{mL}$. It is important to emphasize the advantages and disadvantages of switching the patient's medications. The advantages are the possibilities of avoiding or eliminating adverse effects related to specific HAART medications as was found in the present case. The disadvantages are related to the resistance to HIV and the patient's nonadherence to medications. ${ }^{13}$

Since the clinical features of the oral adverse effect due to NVP are not well known they must be differentiated from other whitish lesions on the oral mucosa. A differential diagnosis may include pseudomenbranous candidiasis and idiopathic or smoking-related leukoplakia. ${ }^{19}$ Pseudomenbranous candidiasis can be differentiated from an oral adverse effect due to NVP as the latter is non-removable. Idiopathic or smoking-related leukoplakia generally occurs in an older population or in smokers. However, this patient was a non-smoker.

HAART has been frequently used in similar cases, but its use has been decreasing due to its adverse effects. The present case suggests a Type II hypersensitivity reaction due to the complement dependent reaction mechanism. This type of reaction may well occur as a reaction to specific medication. ${ }^{20}$

\section{Summary \\ Although HAART is very important in the treatment of HIV, its side effects are responsible for patients' non-adherence to medications. To our knowledge, this case represents the first report of an oral reaction stemming from NVP usage. Nevertheless, more studies are needed to better understand its inner workings. After suspending HAART, the complete resolution of the signs and symptoms was observed. Therefore, physicians and dentists alike must understand how to identify and prevent these adverse effects in order to further improve HIV patient treatments.}

\section{Referneces}

1. Carr A, Cooper DA. Adverse effects of antiretroviral therapy. Lancet 2000; 356 (9239):1423-30.

2. Ena J, Pasquau F. Once-a-day highly active antiretroviral therapy: a systematic review. Clin Infect Dis. 2003; 36(9):1186-90.

3. Hashimoto $\mathrm{H}$, Kapiga $\mathrm{SH}$, Murata Y. Mass treatment with nevirapine to prevent mother-to-child transmission of HIVIAIDS in sub-Saharan African countries. J Obstet Gynaecol Res. 2002; 28(6):313-9.

4. Patton LL, McKaig R, Strauss R, Rogers D, Eron JJ Jr. Changing prevalence of oral manifestations of human immuno-deficiency virus in the era of protease inhibitor therapy. Oral Surg Oral Med Oral Pathol Oral Radiol Endod. 2000; 89(3):299-304.

5. Pirmohamed M, Park BK. HIV and drug allergy. Curr Opin Allergy Clin Immunol. 2001; 1(4):311-6.

6. Schmidt-Westhausen AM, Priepke F, Bergmann FJ, Reichart PA. Decline in the rate of oral opportunistic infections following introduction of highly active antiretroviral therapy. J Oral Pathol Med. 2000; 29(7):336-41.

7. Scully C, Dios PD. Orofacial effects of antiretroviral therapies. Oral Dis. 2001; 7(4):205-10.

8. Tappuni AR, Fleming GJP. The effect of antiretroviral therapy on the prevalence of oral manifestations in HIV-infected patients: a UK study. Oral Surg Oral Med Oral Pathol Oral Radiol Endod. 2001; 92(6):623-8.

9. Cherry-Peppers G, Daniels CO, Meeks V, Sanders CF, Reznik D. Oral manifestations in the era of HAART. J Natl Med Assoc. 2003; 95(2 Suppl 2):21S-32S.

10. Depaola LG. Human immunodeficiency virus disease: natural history and management. Oral Surg Oral Med Oral Pathol Oral Radiol Endod. 2000; 90(3):266-70.

11. Krogstad P, Lee S, Johnson G, Stanley K, McNamara J, Moye J, Jackson JB, Aguayo R, Dieudonne A, Khoury M, Mendez H, Nachman S, Wiznia A. Nucleoside-analogue reverse-transcriptase inhibitors plus nevirapine, nelfinavir, or ritonavir for pretreated children infected with human immunodeficiency virus type 1. Clin Infect Dis. 2002; 34(7):991-1001. 
12. Wetterwald E, Le Cleach I, Michael C, David E, Revuz J. Nevirapine-induced overlap stevensjohnson syndrome/toxic epidermal necrolysis. Br J Dermatol. 1999; 140(5):980-2.

13. Montessori V, Press N, Harris M, Akagi A, Montaner JSG. Adverse effects of antiretroviral therapy for HIV infection. CMAJ. 2004; 170(2):229-38.

14. Bersoff-Matcha SJ, Miller WC, Aberg JA, Van Der Horst C, Hamrick Jr HJ, Powderly WG, Mundy LM. Sex differences in nevirapine rash. Clin Infect Dis. 2001; 32(1):124-9.

15. Montaner JS, Cahn P, Zala C, Cassseti LI, Losso M, Hall DB, Wruck J, McDonough M, Gigliotti M, Robinson PA. Randomized, controlled study of the effects of a short course of prednisone on the incidence of rash associated with nevirapine in patients infected with HIV-1. J Acquir Immune Defic Syndr. 2003; 33(1):41-6.

16. Pollard RB, Robinson P, Dransfield K. Safety profile of nevirapine, a nonnucleoside reverse transcriptase inhibitor for the treatment of human immunodeficiency virus infection. Clin Ther. 1998; 20(6):1071-92.

17. Knobel H, Miro JM, Domingo P, Rivero A, Márquez M, Force L, Gonzalez A, De Miguel V, Sanz J, Boix V, Blanco JL, Locutura J. Failure of a short-term prednisone regimen to prevent nevirapineassociated rash: a double-blind placebo-controlled trial: the GESIDA 09/99 study. J Acquir Immune Defic Syndr. 2001; 28(1):14-8.

18. Bonnet F, Lawson-Ayayi, Thiébaut R, Ramanampamonjy R, Lacoste D, Bernard N, Malvy D, Bonarek M, Djossou F, Beylot J, Dabis F, Morlat P. A cohort study of nevirapine tolerance in clinical practice: French Aquitaine Cohort, 1997-1999. Clin Infect Dis. 2002; 35(10):1231-7.

19. Ficarra G, Flaitz CM, Gaglioti D, Piluso S, Milo D, Adler-Storthz K, Eversole LR. White lichenoid lesions of the buccal mucosa in patients with HIV infection. Oral Surg Oral Med Oral Pathol. 1993; 76(4):460-6.

20. Carder KR. Hypersensitivity reactions in neonates and infants. Dermatol Ther. $2005 ; 18(2): 160-75$.

\section{About the Authors}

\section{Mariola Dutra GontIJo Moura, DDS, M5}

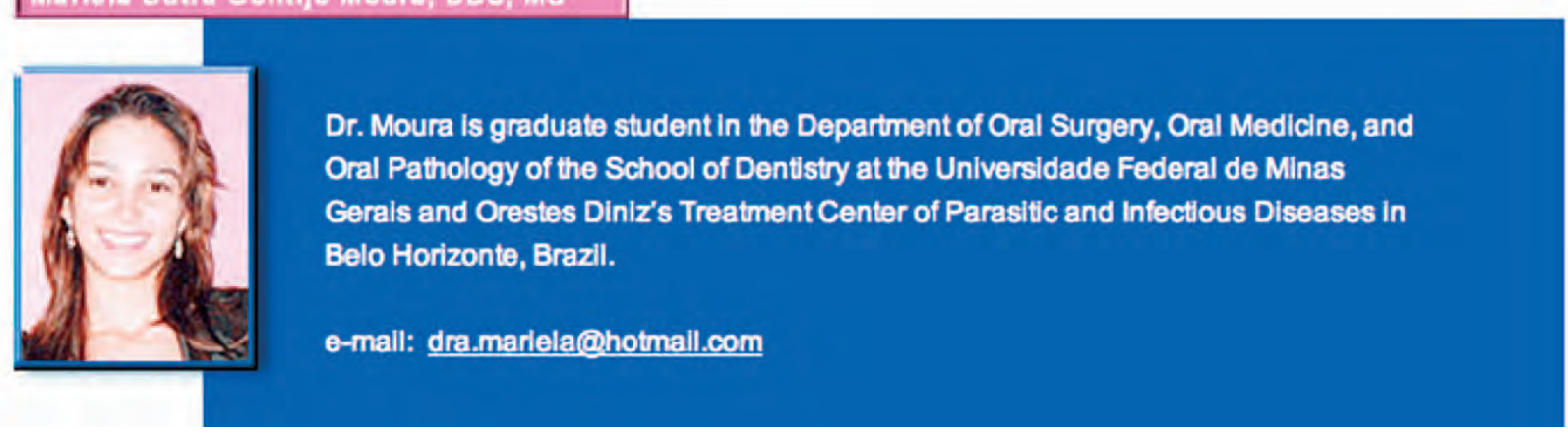

\section{Maria Inds Barrelros Sonna, DDS, MS}

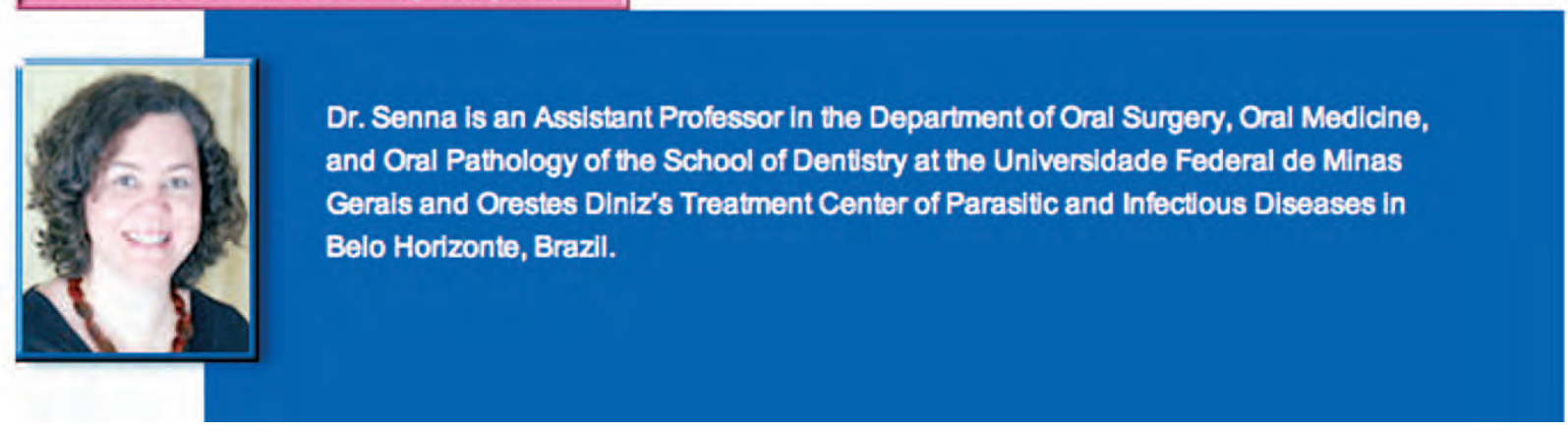



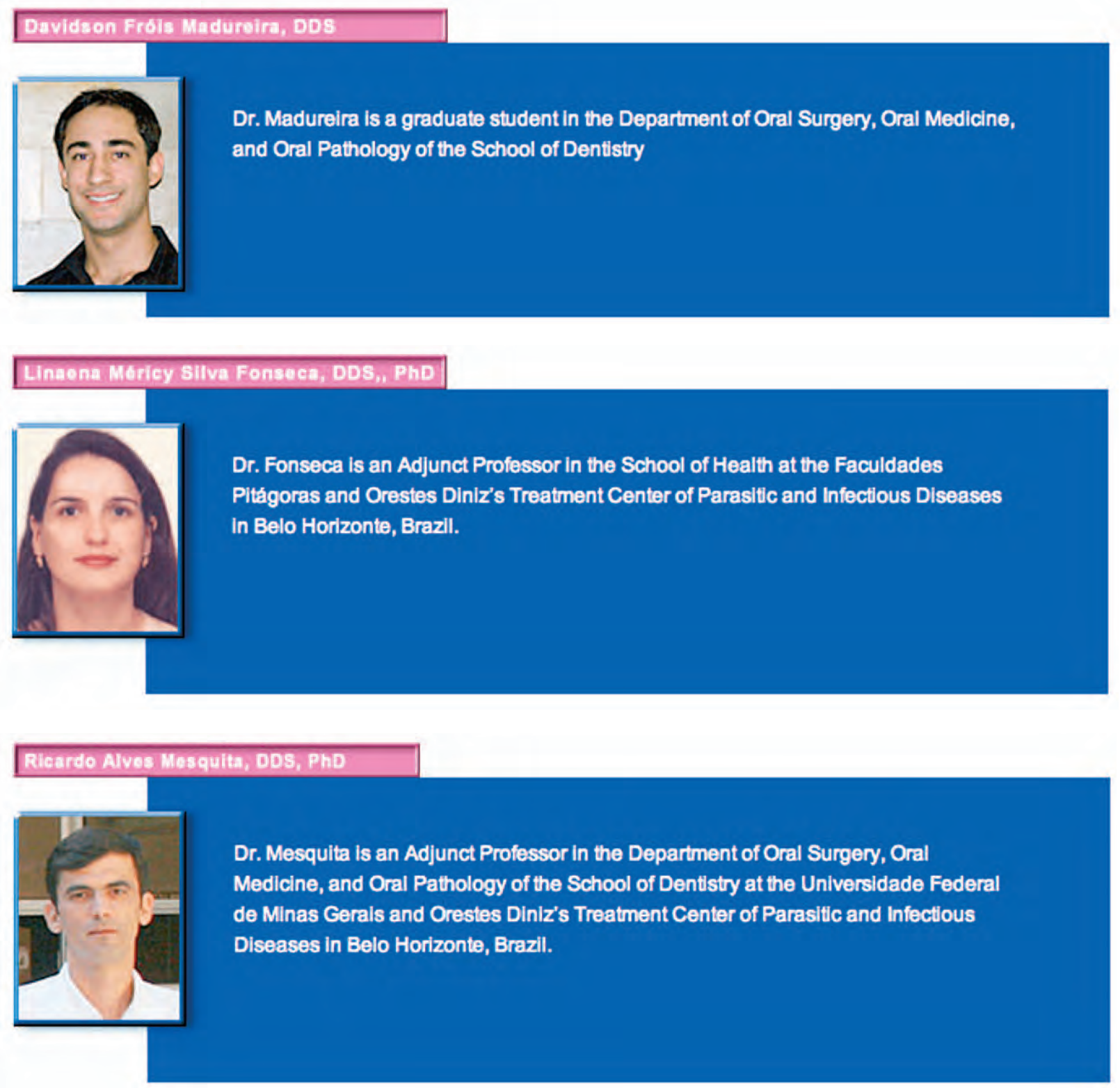